\section{Endoscopic reduction of a jejunogastric intussusception}

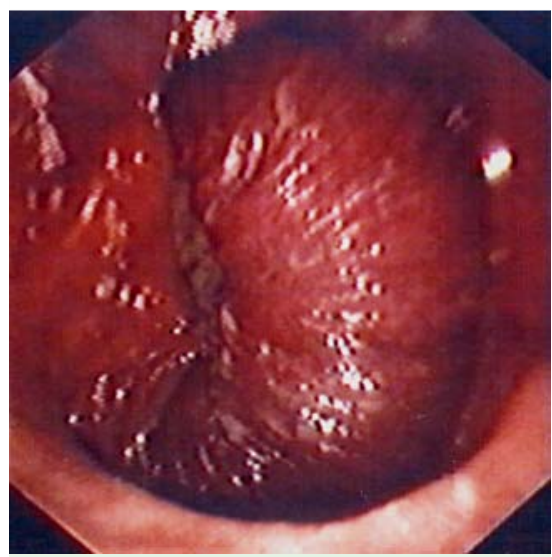

Fig. 1 Upper gastrointestinal endoscopy showing invagination of the efferent loop in a patient with a previous Billroth II gastrectomy.

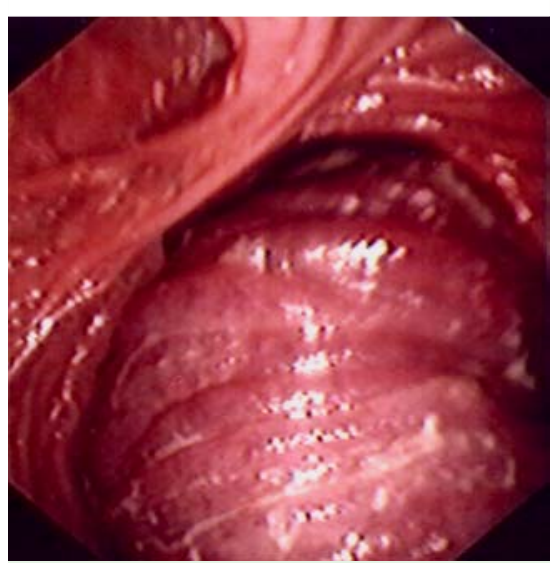

Fig. 2 The mucosa of the invaginated efferent loop appears swollen and congested but viable.

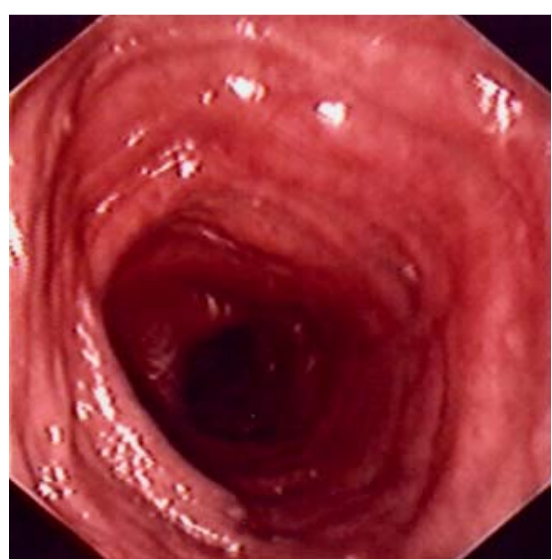

Fig. 3 The appearance after successful endoscopic reduction of the invaginated loop.

Jejunogastric intussusception (JGI) is a rare complication of gastric surgery (incidence $<0.1 \%$ ), in particular of Billroth II proce- dures [1]. Postoperative JGI may present any time between a few days and up to 30 years after surgery [1]. The standard treatment is emergency surgery to prevent the development of severe complications, such as gangrene and perforation of the bowel; however, the perioperative mortality is as high as $10 \%-50 \%$ [2]. Endoscopic management of JGI has been reported in a few cases as a possible alternative to surgery, although the risk of recurrence has been highlighted $[3,4]$. We describe here the successful endoscopic reduction of a JGI without recurrence in a 2-year followup period.

A 66-year-old woman presented with acute abdominal pain, vomiting, and fever. She had a history of splenectomy for trauma as a child and a Billroth II gastrectomy for peptic ulcer disease 35 years previously. Laboratory tests were consistent with cholestasis: bilirubin $58 \mu \mathrm{mol} / \mathrm{L}$ (maximum reference $26 \mu \mathrm{mol} / \mathrm{L}$ ), and elevated alanine aminotransferase, aspartate aminotransferase, and alkaline phosphatase. Initial examination with abdominal ultrasound revealed cholecystolithiasis and a dilated choledochus. Abdominal computed tomography (CT) scan showed gastric distension and the patient was referred for endoscopy. During an upper gastrointestinal endoscopy, an $8 \mathrm{~cm}$ section of the efferent loop of bowel was found to be invaginated into the gastric lumen ( $\bullet$ Fig. 1 ). The mucosa of this loop was swollen and congested but viable ( $\nabla$ Fig. 2 ).

The invaginated loop was endoscopically reduced back to its normal position (๑ Fig. 3).

A further upper gastrointestinal endoscopy carried out 21 hours later showed normal appearances following Billroth II gastrectomy and viable mucosa ( $\bullet$ Fig. 4). The patient recovered fully and was discharged.

A follow-up upper gastrointestinal endoscopy was performed 2 years later and revealed that the efferent loop remained in the normal position and had normal mucosa. This case shows that endoscopic management of JGI is feasible and may help to avoid high-risk surgery without subsequent problems of recurrence.

Endoscopy_UCTN_Code_TTT_1AO_2AN

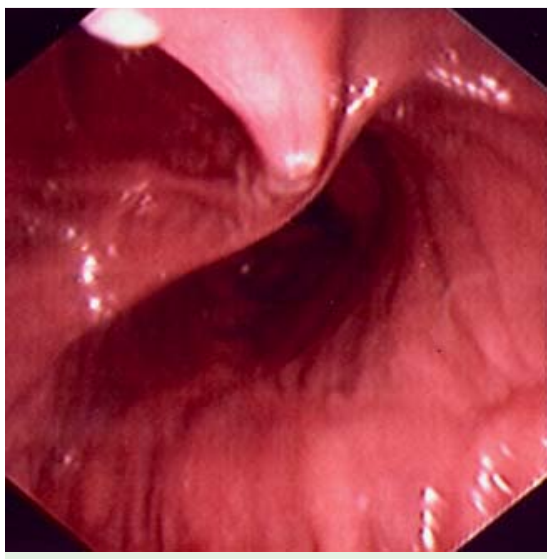

Fig. 4 Follow-up endoscopy performed 21 hours after endoscopic reduction, showing viable mucosa and a normal post Billroth II appearance.

\section{Competing interests: None}

\section{E. Toth ${ }^{1}$, S. Arvidsson ${ }^{2}$, H. Thorlacius ${ }^{2}$}

Department of Clinical Sciences, Endoscopy Unit, Skåne University Hospital, Sweden

2 Departments of Clinical Sciences and Surgery, Skåne University Hospital, Sweden

\section{References}

1 Marx WJ. Reduction of jejunogastric intussusception during upper gastrointestinal examination. AJR Am J Roentgenol 1978; 131: $334-336$

2 AchyutJM, Ishwar JM, Dharmesh B et al. Jejunogastric intussusception: Case report and review of the literature. Dig Endosc 2004; 16: $88-90$

3 Kochhar R, Saxena R, Nagi B et al. Endoscopic management of retrograde jejunogastric intussusception. Gastrointest Endosc 1988; 34: $56-57$

4 Guadagni S, Pistoia M, Catarci M et al. Retrograde jejunogastric intussusception: is endoscopic or surgical management more appropriate? Surg Today 1992; 22: 269-272

\section{Bibliography}

Dol $10.1055 / \mathrm{s}-0030-1256103$

Endoscopy 2011; 43: E63

(C) Georg Thieme Verlag KG Stuttgart · New York . ISSN 0013-726X

\section{Corresponding author \\ E. Toth, MD, PhD}

Department of Clinical Sciences, Endoscopy Unit Skåne University Hospital, Entrance 44, Malmö Lund University 20502 Malmö, Sweden Fax: +46-40-338699

Ervin.Toth@med.lu.se 